nephron

Practice
Nephron 2016;134:215-220

DOI: $10.1159 / 000448184$
Received: May 17, 2016

Accepted after revision: July 2, 2016

Published online: July 22, 2016

\title{
Phosphate Binding Therapy to Lower Serum Fibroblast-Growth-Factor-23 Concentrations in Chronic Kidney Disease: Rationale and Study Design of the Sevelamer on FGF23 Trial (SoFT)
}

\author{
Aaltje Y. Adema ${ }^{a}$ Maarten A. de Jong ${ }^{c}$ Martin H. de Borst ${ }^{c}$ Pieter M. ter Wee ${ }^{a}$ \\ Marc G. Vervloet ${ }^{a, b}$ for the NIGRAM Consortium \\ ${ }^{a}$ Department of Nephrology, VU University Medical Center, and ${ }^{\mathrm{b}}$ Institute for Cardiovascular Research VU (ICaR-VU), \\ Amsterdam, and ' Department of Internal Medicine, Division of Nephrology, University Medical Center Groningen, \\ Groningen, The Netherlands
}

\section{Key Words}

Fibroblast growth factor-23 - Sevelamer $\cdot$ Chronic kidney

disease $\cdot$ Phosphate binding therapy $\cdot$ Sevelamer on

FGF23 trial · SoFT

\section{Abstract}

Background: Increased levels of phosphate and fibroblast growth factor-23 (FGF23) are strong predictors of cardiovascular morbidity and mortality in patients with chronic kidney disease (CKD). Preliminary data suggest that interventions lowering gastro-intestinal phosphate uptake lowers serum FGF23 concentrations and improves cardiovascular risk and subsequently survival. However, data are lacking about the magnitude of effects, the effect in different stages of CKD and whether there is a dose-effect relationship. Methods: Therefore, the Sevelamer on FGF23 Trial (SoFT) is designed as an open-label, single-arm, clinical pilot study aiming to demonstrate the feasibility of a phosphate-restricted diet in combination with the phosphate binder sevelamer to induce an effective, predictable and sustained decrease in FGF23 level in patients with an estimated glomerular filtration rate (eGFR) of $15-90$ or $>90 \mathrm{ml} / \mathrm{min} / 1.73 \mathrm{~m}^{2}$ with proteinuria $>1.0 \mathrm{~g}$ in $24 \mathrm{~h}$ urine collection, despite optimally

\section{KARGER}

E-Mail karger@karger.com www.karger.com/nef

\section{(9) 2016 The Author(s) \\ Published by S. Karger AG, Basel \\ Karger \\ Open access}

This article is licensed under the Creative Commons Attribution NonCommercial-NoDerivatives 4.0 International License (CC BYNC-ND) (http://www.karger.com/Services/OpenAccessLicense). Usage and distribution for commercial purposes as well as any distribution of modified material requires written permission. dosed RAAS blockade, without inducing hypophosphatemia using a forced uptitration treatment regimen aimed at restricting phosphate uptake.

(c) 2016 The Author(s)

Published by S. Karger AG, Basel

\section{Introduction}

Chronic kidney disease (CKD) is an independent risk factor for cardiovascular morbidity and mortality. The putative mechanisms of cardiovascular damage cannot just be explained by traditional risk factors. Currently, treatment of these risk factors, like dyslipidemia and diabetes, does not improve survival in patients with CKD. Moreover, intensive glycemic control might increase mortality in patients with diabetic nephropathy $[1,2]$. Therefore, there is a real need for new treatment targets to improve cardiovascular outcomes. Deregulations in mineral metabolism such as hyperphosphatemia and vitamin $\mathrm{D}$ deficiency are common in CKD patients and have been strongly associated with an increased mortality risk [3-5]. Thus, serum phosphate and vitamin $\mathrm{D}$ have been proposed as targets for intervention to improve cardiovascular outcomes in CKD. Yet, serum phosphate in itself does 
not seem to be the most obvious target, since the increased cardiovascular risk is already present in early stages where phosphate levels are still within the normal range [6]. Furthermore, there is no evidence that supplementation with vitamin D improves clinical outcome [7], and for phosphate lowering therapy, despite decades of application, a definitive proof for improved clinical outcome is lacking. Therefore, additional factors related to mineral metabolism may be more suitable targets for intervention.

Fibroblast growth factor-23 (FGF23) regulates phosphate and vitamin $\mathrm{D}$ metabolism through its strong phosphaturic action and inhibition of vitamin D 1a-hydroxylase activity in proximal tubuli $[8,9]$. It is secreted by osteocytes and osteoblasts, for instance, in response to oral phosphate loading or increased serum $1,25(\mathrm{OH})_{2} \mathrm{D}_{3}$ levels [10-12]. Plasma FGF23 increases as CKD progresses $[13,14]$. At the same time, responsiveness to FGF23 declines as the number of intact nephrons declines. In advanced stages of CKD, increased FGF23 levels fail to further increase the fractional urinary excretion of phosphate, resulting in overt hyperphosphatemia.

In epidemiologic studies, high concentrations of FGF23 have been associated with progressive renal function loss in diabetic and non-diabetic CKD $[15,16]$, with an increased risk of cardiovascular morbidity and mortality [14, 17-19]. The relationship between FGF23 and cardiovascular risk is further supported by epidemiological studies in which elevated FGF23 was associated with endothelial dysfunction $[20,21]$, total body atherosclerosis [22] and LVH [23-25]. However, these studies were not able to prove whether FGF23 directly contributes to a higher cardiovascular risk or rather FGF23 represents an 'innocent bystander' reflecting toxicity of other factors, such as phosphate itself. Recent mechanistic data however are highly suggestive of a direct dismal effect of FGF23 on the cardiovascular system. The study by Faul et al. [26] showed that increased circulating FGF23 in animal models, with or without CKD, induced LVH through a direct effect on the cardiomyocytes. The animal study of Andrukhova et al. [27] showed that an increase in FGF23 leads to increased sodium uptake in the distal tubular cells leading to volume expansion, hypertension and hypertrophy of the heart. Recent observations in humans are in line with the hypothesis that FGF23 can have pathological effects on the cardiovascular system [21,28], particularly through volume overload-related cardiovascular complications, more than atherosclerotic events [29].

These epidemiological and mechanistic studies justify targeting FGF23 in subsequent clinical studies to elucidate whether improvements of circulating FGF23 levels will translate into improved clinical end points. However, prior to executing such trials, detailed knowledge is required about dose-response effects of FGF23-modulating interventions on FGF23 concentrations in CKD.

Principle therapeutic maneuvers to lower FGF23 are dietary phosphate restriction, phosphate binder therapy and, as recently shown, calcimimetic therapy in dialysisdependent stage V CKD [30]. Some small studies suggest that FGF23 can be reduced by dietary phosphate restriction and/or phosphate binding therapy. However, data are still inconsistent, which may relate to differences in the regimen, duration of treatment or patient characteristics [10,31-33]. In addition, data are lacking about the magnitude of effects, the potency of phosphate binder therapy to reduce FGF23 in different stages of CKD and the presence or absence of a dose-effect relationship. On top of that, as our data showed that proteinuria is associated with FGF23 levels [34], it is unknown how proteinuria interacts with the FGF23-lowering potency of phosphate binder therapy. To address these issues, the Sevelamer on FGF23 Trial (SoFT) study was designed as an open-label, single-arm, clinical pilot study aiming to demonstrate the feasibility to induce an effective, predictable and sustained decrease in FGF23 level in patients with an estimated glomerular filtration rate (eGFR) of $15-90$ or $>90 \mathrm{ml} / \mathrm{min} / 1.73 \mathrm{~m}^{2}$ with proteinuria $>1.0 \mathrm{~g}$ in $24 \mathrm{~h}$ urine collection, despite optimally dosed RAAS blockade, without inducing hypophosphatemia using a forced uptitration treatment regimen aimed at restricting phosphate uptake. We expect that instead of being titrated to a specific value of phosphate, a combination of dietary phosphate restriction and non-calcium-based binders can induce a decline of FGF23. For this, our hypothesis is that doses are needed that go beyond what is needed for phosphate control. If this is confirmed in the SoFT trial, this strategy can be applied to target FGF23 to test the hypothesis that a decline of FGF23, instead of phosphate, can lead to improvement of risk.

\section{Study Protocol}

\section{Study Design and Organization}

The SoFT is an investigator-initiated, prospective, multicenter, open-label, single-arm trial in subjects with an eGFR of 15-90 or $>90 \mathrm{ml} / \mathrm{min} / 1.73 \mathrm{~m}^{2}$ with proteinuria $>1.0 \mathrm{~g}$ in $24 \mathrm{~h}$ urine collection, despite optimally dosed RAAS blockade. The study is being conducted according to the principles of the Declaration of Helsinki and in accordance with the Medical Research Involving $\mathrm{Hu}-$ man Subjects Act (WMO, The Netherlands). The study has been approved by the Medical Ethical Committee of the VU University Medical Center Amsterdam, The Netherlands (METC 2013.261). 
Table 1. Eligibility criteria of the SoFT study

\begin{tabular}{|c|c|}
\hline Inclusion criteria & Exclusion criteria \\
\hline Male and female patients & Use of antiarrhythmic agents or anticonvulsants \\
\hline $\begin{array}{l}\text { eGFR of } 15-90 \text { or }>90 \mathrm{ml} / \mathrm{min} / 1.73 \mathrm{~m}^{2} \text { with proteinuria }>1.0 \mathrm{~g} \text { in } \\
24 \text { h urine collection, despite optimally dosed RAAS blockade }\end{array}$ & $\begin{array}{l}\text { Patients with }>1.0 \text { g proteinuria in } 24 \mathrm{~h} \text { urine collection not } \\
\text { receiving RAAS blockade therapy }\end{array}$ \\
\hline Age $\geq 18$ years & Patients taking other experimental (i.e. non marketed) therapies \\
\hline Serum phosphate levels between 0.80 and $1.45 \mathrm{mmol} / \mathrm{l}$ & $\begin{array}{l}\text { Pregnant or nursing (lactating) women, where pregnancy is } \\
\text { defined as a state of a female after conception and until the } \\
\text { termination of gestation, confirmed by a positive } \beta \text {-HCG urine } \\
\text { test }(>5 \mathrm{U} / \mathrm{l})\end{array}$ \\
\hline Not taking any phosphate binding therapy & Change in vitamin $\mathrm{D}$ dose 4 weeks prior to baseline \\
\hline Informed consent provided & $\begin{array}{l}\text { History of parathyroidectomy, arrhythmias, seizures, bowel } \\
\text { obstruction or malabsorption, kidney transplantation, autosomal } \\
\text { dominant polycystic kidney disease } \\
\text { Hyperparathyroidism (e.g. PTH levels }>2 \times \text { upper normal } \\
\text { defined by the reference values of each participating center) } \\
\text { Body mass index }>35 \mathrm{~kg} / \mathrm{m}^{2} \\
\text { Allergy or intolerance for study medication }\end{array}$ \\
\hline
\end{tabular}

Participation in the study is on voluntary basis. Patients will not receive any financial support or priority for treatment of other diseases during this study.

\section{Study Population}

The SoFT study recruits patients $\geq 18$ years, with CKD stage I with $>1$ g proteinuria in $24 \mathrm{~h}$ urine collection despite optimally dosed RAAS blockade and CKD stages II-IV, with a serum phosphate level between 0.80 and $1.45 \mathrm{mmol} / \mathrm{l}$ and not taking any phosphate binder therapy. Patients are stratified according to CKD stages (KDIGO clinical practice guideline for the evaluation and management of CKD of 2012) [35]. Furthermore, eligible patients were not allowed to start vitamin $\mathrm{D}$ suppletion or change their vitamin D dose within 4 weeks prior to start of the study or during the study, as this might interfere with the study end point. Patients who also met the other prespecified eligibility criteria (table 1) and provided written informed consent were enrolled. Patient enrolment started during February 2014 and is ongoing.

\section{Intervention}

All patients already receive standard care before inclusion, which includes an advice to restrict sodium intake to $<100 \mathrm{mmol} \mathrm{Na}^{+} /$day, statin therapy when LDL cholesterol $>2.5 \mathrm{mmol} / \mathrm{l}$, antihypertensive treatment (defined as a systolic blood pressure $\geq 140 \mathrm{~mm} \mathrm{Hg}$ and/or a diastolic blood pressure $\geq 90 \mathrm{~mm} \mathrm{Hg}$ ), using ACE inhibitors or ARBs in case of proteinuria above $0.5 \mathrm{~g} / 24 \mathrm{~h}$ and using glucoselowering drugs if indicated (according to the Dutch Guideline Cardiovascular Risk Management 2006). At baseline, all the patients are placed on a phosphate-restricted diet aimed at a phosphate intake $<1,000 \mathrm{mg}$ /day guided by instructions of a dietician. Afterward, the researcher will examine the dietary compliance of phosphate and sodium restriction at every visit. After the second week, all patients initiate treatment with $1,600 \mathrm{mg}$ sevelamer carbonate per day in di- vided doses, which is uptitrated with 2 weekly increments from $1,600 \mathrm{mg}$ to daily dosages of 3,$200 ; 4,800 ; 6,400$ and $8,000 \mathrm{mg}$, provided the serum phosphate concentrations do not drop below 0.8 $\mathrm{mmol} / \mathrm{l}$. When the highest tolerable dose is reached, based on serum phosphate concentration and side effects, that dose will be maintained for 6 weeks, after which sevelamer and dietary intervention are stopped (fig. 1). The total study period is 18 weeks.

\section{Clinical Laboratory Tests}

Serum phosphate as well as concentrations of protein, creatinine, phosphate sodium, and calcium in first morning spot urine are measured every study visit. A tube containing a protease inhibitor is being drawn every study visit and stored in the freezer in order to measure cFGF23 concentrations at the end of the study. cFGF23 will be measured with Elisa kits (Immutopics, Inc., San Clemente, Calif., USA), following manufacturer's protocols with intra-assay variation of $<5 \%$ and inter-assay variation of $<10 \%$. Once a month, serum creatinine, sodium, potassium, calcium, glucose and albumin concentrations are measured. Total blood count, serum $25(\mathrm{OH})_{2} \mathrm{D}_{3}$ and parathyroid hormone levels are measured at baseline and week 16 of the study; 24 -hour urine will be collected as well at these 2 visits to measure concentrations of phosphate, creatinine, protein, urea, calcium and sodium. At baseline and at the end of the study serum, EDTA-plasma, heparin-plasma and urine will be stored for post hoc studies.

\section{Safety}

In general, the risk for participation in this study is estimated to be low. Sevelamer carbonate is widely prescribed in the clinical setting for the treatment of hyperphosphatemia in CKD patients. No serious side effects are expected of the sevelamer carbonate dosages used in this study. Gastrointestinal complaints like nausea, vomiting, constipation or diarrhea are the most likely side effects 


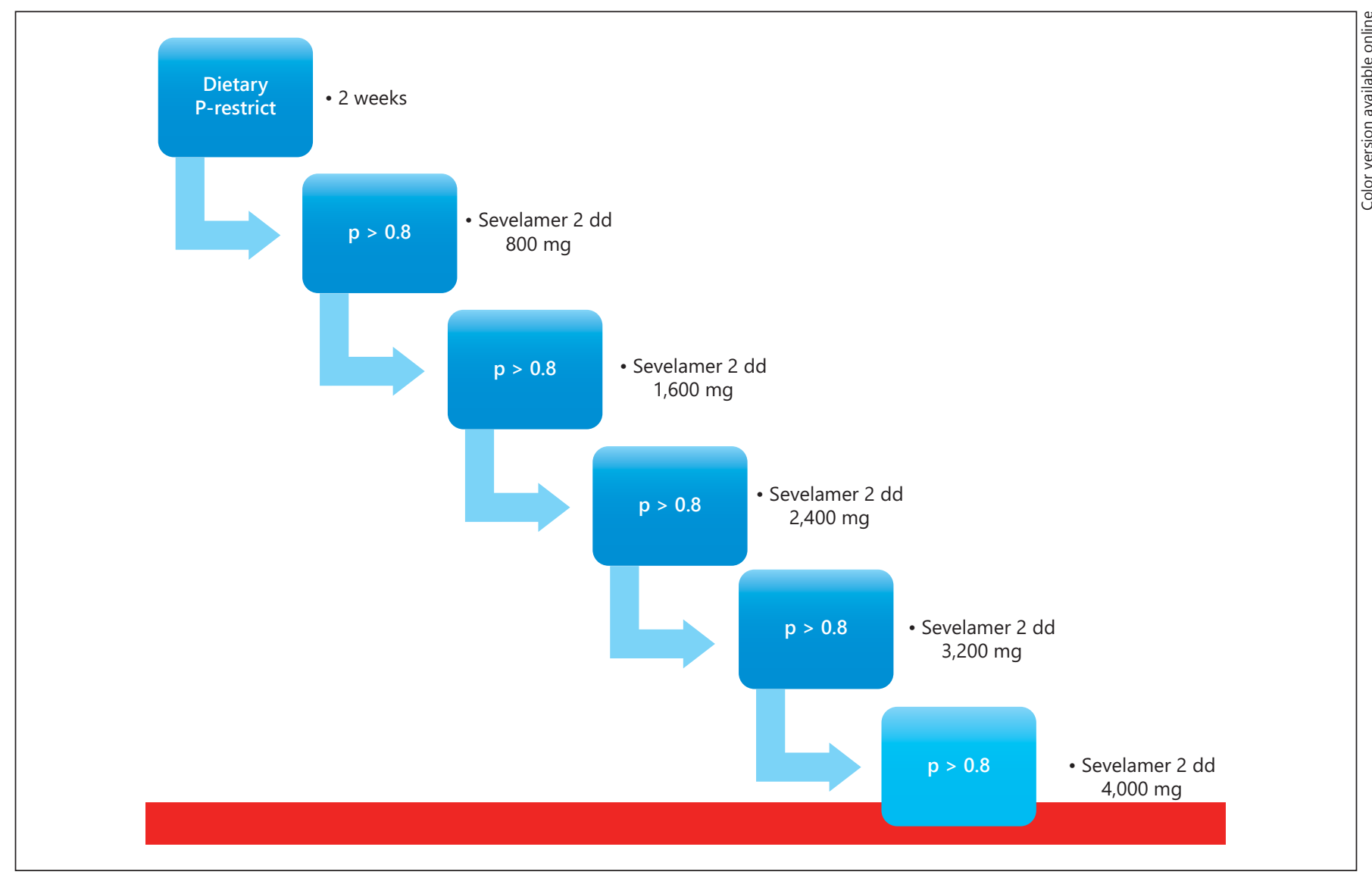

Fig. 1. Medication titration schedule of the SoFT study.

to occur. The biweekly evaluation of serum phosphate levels ensures that hypophosphatemia will be noticed in an early phase. Therefore, symptomatic hypophosphatemia is not expected and has not occurred so far. If hypophosphatemia is noticed, the dosing scheme is adapted per protocol (table 2). Adverse events and vital signs are monitored at every study visit.

\section{Study End Points}

The primary study end point is the absolute change in cFGF23 from baseline to end of treatment for the highest (tolerable) dose of sevelamer carbonate. The secondary end point is decline in cFGF23 from baseline to end of treatment per stage of CKD. Other prespecified explorative variables include plasma levels of creatinine, phosphate, albumin, calcium, $25(\mathrm{OH})_{2} \mathrm{D}$ and $1,25(\mathrm{OH})_{2} \mathrm{D}_{3}$ and PTH. Twenty-four hours urine collections were used for measurements of phosphate and calcium excretion and proteinuria. In addition, creatinine clearance and TmP/GFR were calculated.

\section{Sample Size}

Formal sample size calculations are not possible due to lack of sufficient data in the literature. However, based on the study of Oliveira et al. [31], an approximately 50\% decline of intact FGF23 is anticipated in the $6,400 \mathrm{mg}$ dose of sevelamer, which was statis-
Table 2. Dose adjustments of sevelamer carbonate according to serum phosphate levels

\section{Phosphate level, Action} $\mathrm{mmol} / \mathrm{l}$

\begin{tabular}{ll}
\hline$>0.8$ & Proceed to next dose level \\
\hline $0.7-0.8$ & No dose increase \\
\hline $0.6-0.7$ & Dose reduction to previous level \\
\hline$<0.6$ & $\begin{array}{l}\text { Stop sevelamer for } 2 \text { weeks, resume } \\
\text { sevelamer at lower dose level }\end{array}$ \\
\hline
\end{tabular}

$<0.6$ at dose level 1 Stop study medication, continue monitoring

tically significant in 21 patients in stage III CKD. Since it is unknown if cFGF23 response might be different, we aim at 45 patients to complete the protocol, to detect a significant effect on cFGF23 on the highest dose of $8,000 \mathrm{mg} /$ day. Since a $25 \%$ dropout can be expected, based on previous studies using sevelamer, 60 patients will be recruited aiming at equal distribution for stages of CKD. 
Statistical Analysis

We will use standard descriptive statistics to assess baseline clinical and laboratory data at enrolment. Statistical analysis of the primary end point will be performed using Generalize Estimating Equations, a technique suitable for longitudinal data analysis, using current versions of SPSS version 22, Stata version 14 and MLwiN version 2.36. Adjustments for stage of CKD and sevelamer dose will be made. In general, $\mathrm{p}<0.05$ will be considered to be statistically significant. Patients who dropout during the study period will be analyzed until the last hospital visit at which data have been collected, except for dropout due to screening failure.

\section{Trial Status}

Patient enrolment started at February 2014; the expected date of last patient enrolment will be mid-2017. The study will end 18 weeks after the last patient enrolment.

Currently, 20 participants are included of which 17 participants completed the study and there were 3 dropouts. Forty-five percent were men, the mean age was $58 \pm 14$ years and 5 participants had an eGFR between 60 and $89 \mathrm{ml} / \mathrm{min} / 1.73 \mathrm{~m}^{2}$ and 15 participants had an eGFR between 30 and $59 \mathrm{ml} / \mathrm{min} / 1.73 \mathrm{~m}^{2}$. None of them had an eGFR between $5-29$ or $\geq 90 \mathrm{ml} / \mathrm{min} / 1.73 \mathrm{~m}^{2}$.

\section{Discussion}

As pointed out in the introduction, both epidemiological and mechanistic studies consistently point to a causal role for FGF23 in CKD-related morbidity. However, definitive proof of this causal role should come from a prospective clinical trial. Principle maneuvers currently available to target FGF23 are dietary phosphate restriction, phosphate binding therapy and calcimimetic therapy, with the latter option not routinely available for predialysis CKD patients. Data on the FGF23-lowering effect of the various types of phosphate binders appear to be most consistent for sevelamer [28, 31, 32, 36-40]. Calcium-based phosphate binders may not reduce or may even increase FGF23 [28, 39, 41].
However, no formal dose-response relationship between sevelamer carbonate and FGF23 has been established. Moreover, there is no data on the uptitration of sevelamer carbonate beyond the point of reaching normal serum phosphate concentrations that may induce a further decline in FGF23. Data from the SoFT trial are required before initiating a prospective trial aimed at reduction of clinical end points by targeting FGF23 in patients with CKD.

\section{Clinical Trial Registration}

2012-002967-84 (EudraCT number), NL40300.029.13 (Dutch Trial Register).

\section{Acknowledgment}

This work is supported by a consortium grant from the Dutch Kidney Foundation (NIGRAM Consortium, grant No. CP10.11). The funders had no role in the study design and report of this trial. PI's of NIGRAM: R. Bindels and J.G. Hoenderop, RadboudUMC, M.H. de Borst, J.L. Hillebrands and G.J. Navis UMCG, P.M. ter Wee and M.G. Vervloet, Vumc.

\section{Disclosure Statement}

P.M.W.: speakers fee and travel grants from FMC, advisory board Amgen. M.G.V.: honoraria and research grants form FMC/ Vifor, Amgen, Baxter, AbbVie. All authors have no conflicts of interest.

\section{Statement of Ethics}

The SoFT trial has been approved by the appropriate ethics committee and all participants give informed consent.

\section{References}

1 Kalantar-Zadeh K, Block G, Humphreys MH, Kopple JD: Reverse epidemiology of cardiovascular risk factors in maintenance dialysis patients. Kidney Int 2003;63:793-808.

2 de Borst MH, Navis G: Diabetes: risks of strict glycaemic control in diabetic nephropathy. Nat Rev Nephrol 2015;11:5-6.

3 Block GA, Klassen PS, Lazarus JM, Ofsthun N, Lowrie EG, Chertow GM: Mineral metabolism, mortality, and morbidity in maintenance hemodialysis. J Am Soc Nephrol 2004; 15:2208-2018.
4 Kalantar-Zadeh K, Kuwae N, Regidor DL, Kovesdy CP, Kilpatrick RD, Shinaberger CS, et al: Survival predictability of time-varying indicators of bone disease in maintenance hemodialysis patients. Kidney Int 2006;70:771780.

5 Wolf M, Shah A, Gutierrez O, Ankers E, Monroy $\mathrm{M}$, Tamez $\mathrm{H}$, et al: Vitamin D levels and early mortality among incident hemodialysis patients. Kidney Int 2007;72:1004-1013.

6 Go AS, Chertow GM, Fan D, McCulloch CE, Hsu CY: Chronic kidney disease and the risks of death, cardiovascular events, and hospitalization. N Engl J Med 2004;351:1296-1305.

7 Palmer SC, McGregor DO, Craig JC, Elder G, Macaskill P, Strippoli GF: Vitamin D compounds for people with chronic kidney disease requiring dialysis. Cochrane Database Syst Rev 2009;4:CD005633.

8 Yamashita T, Yoshioka M, Itoh N: Identification of a novel fibroblast growth factor, FGF23 , preferentially expressed in the ventrolateral thalamic nucleus of the brain. Biochem Biophys Res Commun 2000;277:494-498. 
-9 Shimada T, Hasegawa H, Yamazaki Y, Muto T, Hino R, Takeuchi Y, et al: FGF-23 is a potent regulator of vitamin $\mathrm{D}$ metabolism and phosphate homeostasis. J Bone Miner Res 2004; 19:429-435.

10 Vervloet MG, van Ittersum FJ, Buttler RM, Heijboer AC, Blankenstein MA, ter Wee PM: Effects of dietary phosphate and calcium intake on fibroblast growth factor-23. Clin J Am Soc Nephrol 2011;6:383-389.

11 Quarles LD: Endocrine functions of bone in mineral metabolism regulation. J Clin Invest 2008;118:3820-3828.

12 Prie D, Urena Torres P, Friedlander G: Latest findings in phosphate homeostasis. Kidney Int 2009;75:882-889.

13 Larsson T, Nisbeth U, Ljunggren O, Juppner $\mathrm{H}$, Jonsson KB: Circulating concentration of FGF-23 increases as renal function declines in patients with chronic kidney disease, but does not change in response to variation in phosphate intake in healthy volunteers. Kidney Int 2003;64:2272-2279.

14 Isakova T, Xie H, Yang W, Xie D, Anderson AH, Scialla J, et al: Fibroblast growth factor 23 and risks of mortality and end-stage renal disease in patients with chronic kidney disease. JAMA 2011;305:2432-2439.

15 Titan SM, Zatz R, Graciolli FG, dos Reis LM, Barros RT, Jorgetti V, et al: FGF-23 as a predictor of renal outcome in diabetic nephropathy. Clin J Am Soc Nephrol 2011;6:241-247.

16 Fliser D, Kollerits B, Neyer U, Ankerst DP, Lhotta K, Lingenhel A, et al: Fibroblast growth factor 23 (FGF23) predicts progression of chronic kidney disease: the mild to moderate kidney disease (MMKD) study. J Am Soc Nephrol 2007;18:2600-2608.

$\checkmark 17$ Gutierrez OM, Mannstadt M, Isakova T, Rauh-Hain JA, Tamez H, Shah A, et al: Fibroblast growth factor 23 and mortality among patients undergoing hemodialysis. N Engl J Med 2008;359:584-592.

18 Kendrick J, Cheung AK, Kaufman JS, Greene T, Roberts WL, Smits G, et al: FGF-23 associates with death, cardiovascular events, and initiation of chronic dialysis. J Am Soc Nephrol 2011;22:1913-1922.

-19 Parker BD, Schurgers LJ, Brandenburg VM, Christenson RH, Vermeer C, Ketteler M, et al: The associations of fibroblast growth factor 23 and uncarboxylated matrix Gla protein with mortality in coronary artery disease: the heart and soul study. Ann Intern Med 2010; 152:640-648.
20 Mirza MA, Larsson A, Lind L, Larsson TE: Circulating fibroblast growth factor-23 is associated with vascular dysfunction in the community. Atherosclerosis 2009;205:385390.

21 Yilmaz MI, Sonmez A, Saglam M, Yaman H, Kilic S, Demirkaya E, et al: FGF-23 and vascular dysfunction in patients with stage 3 and 4 chronic kidney disease. Kidney Int 2010;78: 679-685.

22 Mirza MA, Hansen T, Johansson L, Ahlstrom H, Larsson A, Lind L, et al: Relationship between circulating FGF23 and total body atherosclerosis in the community. Nephrol Dial Transplant 2009;24:3125-3131.

$>23$ Gutierrez OM, Januzzi JL, Isakova T, Laliberte K, Smith K, Collerone G, et al: Fibroblast growth factor 23 and left ventricular hypertrophy in chronic kidney disease. Circulation 2009;119:2545-2552.

24 Mirza MA, Larsson A, Melhus H, Lind L, Larsson TE: Serum intact FGF23 associate with left ventricular mass, hypertrophy and geometry in an elderly population. Atherosclerosis 2009;207:546-551.

25 Seiler S, Cremers B, Rebling NM, Hornof F, Jeken J, Kersting S, et al: The phosphatonin fibroblast growth factor 23 links calciumphosphate metabolism with left-ventricular dysfunction and atrial fibrillation. Eur Heart J 2011;32:2688-2696.

-26 Faul C, Amaral AP, Oskouei B, Hu MC, Sloan A, Isakova T, et al: FGF23 induces left ventricular hypertrophy. J Clin Invest 2011;121: 4393-4408.

27 Andrukhova O, Slavic S, Smorodchenko A, Zeitz U, Shalhoub V, Lanske B, et al: FGF23 regulates renal sodium handling and blood pressure. EMBO Mol Med 2014;6:744-759.

28 Yilmaz MI, Sonmez A, Saglam M, Yaman H, Kilic S, Eyileten T, et al: Comparison of calcium acetate and sevelamer on vascular function and fibroblast growth factor 23 in CKD patients: a randomized clinical trial. Am J Kidney Dis 2012;59:177-185.

29 Scialla JJ, Xie H, Rahman M, Anderson AH, Isakova T, Ojo A, et al: Fibroblast growth factor-23 and cardiovascular events in CKD. J Am Soc Nephrol 2014;25:349-360.

30 Moe SM, Chertow GM, Parfrey PS, Kubo Y, Block GA, Correa-Rotter R, et al: Cinacalcet, fibroblast growth factor-23, and cardiovascular disease in hemodialysis: the evaluation of cinacalcet $\mathrm{HCl}$ therapy to lower cardiovascular events (EVOLVE) trial. Circulation 2015; 132:27-39.

>31 Oliveira RB, Cancela AL, Graciolli FG, Dos Reis LM, Draibe SA, Cuppari L, et al: Early control of PTH and FGF23 in normophosphatemic CKD patients: a new target in CKDMBD therapy? Clin J Am Soc Nephrol 2010; 5:286-291.
32 Gonzalez-Parra E, Gonzalez-Casaus ML, Galan A, Martinez-Calero A, Navas V, Rodriguez $\mathrm{M}$, et al: Lanthanum carbonate reduces FGF23 in chronic kidney disease stage 3 patients. Nephrol Dial Transplant 2011;26: 2567-2571.

33 Isakova T, Gutierrez OM, Smith K, Epstein M, Keating LK, Juppner H, et al: Pilot study of dietary phosphorus restriction and phosphorus binders to target fibroblast growth factor 23 in patients with chronic kidney disease. Nephrol Dial Transplant 2011;26:584-591.

34 Vervloet MG, van Zuilen AD, Heijboer AC, ter Wee PM, Bots ML, Blankestijn PJ, et al: Fibroblast growth factor 23 is associated with proteinuria and smoking in chronic kidney disease: an analysis of the MASTERPLAN cohort. BMC Nephrol 2012;13:20.

$>35$ Kidney Disease: Improving Global Outcomes (KDIGO) CKD Work Group: KDIGO 2012 clinical practice guideline for the evaluation and management of chronic kidney disease. Kidney Int Suppl 2013;3:1-150.

-36 Isakova T, Barchi-Chung A, Enfield G, Smith K, Vargas G, Houston J, et al: Effects of dietary phosphate restriction and phosphate binders on FGF23 levels in CKD. Clin J Am Soc Nephrol 2013;8:1009-1018.

37 Bleskestad IH, Bergrem H, Hartmann A, Godang K, Goransson LG: Fibroblast growth factor 23 and parathyroid hormone after treatment with active vitamin D and sevelamer carbonate in patients with chronic kidney disease stage $3 \mathrm{~b}$, a randomized crossover trial. BMC Nephrol 2012;13:49.

38 Spatz C, Roe K, Lehman E, Verma N: Effect of a non-calcium-based phosphate binder on fibroblast growth factor 23 in chronic kidney disease. Nephron Clin Pract 2013;123:61-66.

39 Block GA, Wheeler DC, Persky MS, Kestenbaum B, Ketteler M, Spiegel DM, et al: Effects of phosphate binders in moderate CKD. J Am Soc Nephrol 2012;23:1407-1415.

$>40$ Koiwa F, Kazama JJ, Tokumoto A, Onoda N, Kato H, Okada T, et al: Sevelamer hydrochloride and calcium bicarbonate reduce serum fibroblast growth factor 23 levels in dialysis patients. Ther Apher Dial 2005;9:336339.

41 Cancela AL, Oliveira RB, Graciolli FG, dos Reis LM, Barreto F, Barreto DV, et al: Fibroblast growth factor 23 in hemodialysis patients: effects of phosphate binder, calcitriol and calcium concentration in the dialysate. Nephron Clin Pract 2011;117:c74-c82. 